whole of the anterior part of the larynx seems to be filled up with growths; the posterior wall alone is free.

A Shiagram of a Foreign Body in the CEsophagus. Mr. DE SAN'I showed a skiagram of a halfpenny tightly wedged in the œsophagus, opposite the level of the top of the sternum.

The patient was a child of two years eleven months, who had swallowed a halfpenny eleven days before Mr. de Santi saw him.

The mother of the child stated that she had carefully examined the stools passed, but had seen no halfpenny. Beyond having occasional attacks of vomiting, there had been no symptoms.

When brought to Mr. de Santi, the mother stated the child complained of pain in the right iliac fossa. On examination, the child cried on that locality being pressed.

Mr. de Santi ordered the air-passages to be skiagraphed. The halfpenny was then clearly seen in the cesophagus. Under chloroform the top of the coin was with difficulty felt with the tip of the index-finger. It was extracted by means of the coincatcher, although tightly wedged.

The child made an uninterrupted recovery. The interest of the case lay: (1) in the length of time the coin had remained impacted in the cesophagus, i.e., twelve days; $(2)$ the absence of any localizing symptoms, such as pain, dysphagia, or dyspnea: (3) the presence of pain around the cxcum, suggesting lodgment of the coin in that neighbourhood; (1) the absence of any inflammation or ulceration in the neck where the coin was wedged.

\title{
Abstracts.
}

\section{DIPHTHERIA, Etc.}

Richmond and Salter.-The Etiological Significance of the Diphtheric Bacillus and its Variants. "Guy's Hospital Reports, 1896" (just published).

In 114 cases of diphtheria, of all degrees of severity, the authors have analyzed the morphological variety of bacillus present, the degree of virulence, and the quantitative toxicity.

They have come to the following conclusions, amongst others, that:

1. The virulence of a diphtheria bacillus for guinea-pigs bears no relation to the severity or malignancy of the disease in the patient from which the organism was derived.

2. No relation exists between the length of the bacillus and the severity of the disease in man. (They are thus entirely opposed to Martin, 1890, and Washbourn, Goodall, and Card, 1894.) 
3. The so-called pseudo-diphtheria bacillus can only be regarded as a mild and attenuated, but still pathogenic variety of the true causal agent of diphtheria.

4. Diphtheria has as its immediate cause the Klebs-Lötfler bacillus and its variants, including all the so-called non-pathogenic forms.

5. For the production of the malady in the individual, and especially for the occurrence of the disease in epidemic form, several other factors must be considered. These are climatic, seasonal, etc., and the autiors wish to adopt provisionally the old term "genius epidemicus."

For details of the mode of investigation, and for other valuable points, the reader is referred to the original paper, which is most excellent and instructive.

Atuood Thorne.

\section{Smith, Captain Frederick (Royal Army Medical Corps). - Diphtheria} Bacilli in the Crine. " Lancet," November 19, 1898.

A guinea-pig which had been some days before injected with live broth culture of diphtheria bacilli was noticed to be passing hæmorrhagic urine, and the idea at once suggested itself, If blood, why not bacilli? The animal was killed and opened aseptically, and the bladder was exposed. The viscus was touched with a heated glass rod, and pierced at the sterilized spot by a glass pipette. Bloody urine thus obtained in the pipette was run over the surface of coagulated serum in a Petrie dish. After incubation a copious growth of typical KlebsLöfller bacilli was the result.

A second guinea pig was injected with a living culture. The animal was killed five hours later, and the urine was obtained aseptically in the manner above detailed. The urine was normal in appearance, but a plentiful growth of diphtheria bacilli on serum was obtained.

The result in the case of the second guinea-pig is somewhat surprising considering the short time which elapsed between injection and death. These facts go to prove that, in the guinea-pig at any rate, bacilli in the blood-stream are some of them eliminated alive through the kidneys. It does not follow, of course, that diphtheria bacilli are passed alive through the kidney of a human being suffering from diphtherial disease. For all that, the results obtained suggest that, at least in hæmorrhagic diphtheria, bacilli will be found in the urine. It may further be anticipated that in all cases in which the bacillus (whether in small or large numbers) escapes into the bloodstream it will be present in the urine. It may be predicted even that, in order to prove the presence of the bacillus in the blood, search for it will be made in the urine in future. The practical bearing of this question is important from the public health point of view. If the urine of diphtheria patients is liable to contain the bacillus, the urine and frees (for the solid excreta are almost invariably mixed with more or less urine) will have to he disinfected just as rigorously as those of patients suffering from enteric fever. Those bygienists who have so strenuously maintained that there is a connection between general insanitation, middens, etc., and diphtheria will have a new fact to strengthen their argument.

Stc'lair Thomson. 